\title{
The Adjuvant Protective Effect of Resveratrol on Cisplatin-Induced Liver Toxicity in Male Albino Rats \\ Huda I. Abd-Elhafiz ${ }^{1}$, Noha M. Issa ${ }^{2}$
}

Departments of ${ }^{1}$ Clinical Pharmacology and ${ }^{2}$ Anatomy and Embryology, Faculty of Medicine, Menoufia University *Corresponding author: Noha Mohey Issa, Mobile: (+20)01005780374, E-mail: drnohaissa@ yahoo.com

\begin{abstract}
Background: Cisplatin is antineoplastic drug associated with hepatotoxicity due to oxidative stress. Resveratrol has antioxidant effect so it could protect the liver cell. Objective: the aim of this work was to investigate the possible protective effects of resveratrol on hepatotoxicity caused by cisplatin drug in rats.

Materials and Methods: forty male albino rats were randomly divided into four groups: group I (control group): was maintained throughout the experiment without any treatment. Group II (resveratrol group) that received resveratrol daily in a dose of $25 \mathrm{mg} / \mathrm{kg}$ intraperitoneally for 21 days. Group III (cisplatin group) that received single intraperitoneal injection of cisplatin in a dose of $7.5 \mathrm{mg} / \mathrm{kg}$ at the $16^{\text {th }}$ day of the experiment. Group IV (protected group) that received resveratrol in a dose of $25 \mathrm{mg} / \mathrm{kg}$ intraperitoneally for 21 days and cisplatin at $16^{\text {th }}$ day of the experiment. Body and liver weight were estimated, biochemical measurements and histopathological study of the liver tissue were done.
\end{abstract}

Results: showed significant preservation of the liver function and histological structure.

Conclusion: it is concluded that resveratrol could protect liver against cisplatin side effects.

Keywords: Cisplatin, Liver toxicity, Resveratrol.

\section{INTRODUCTION}

Cisplatin (cis-diamminedichloroplatinum II, CP) is one of the antineoplastic drugs and of a class of alkylating agents that are commonly used in the treatment of many neoplastic disorders like gut, ovarian, cervical, and germ cell tumors ${ }^{(\mathbf{1})}$. Moreover, cisplatin could discontinue the tumor growth by means of cross-linking guanine bases in DNA double helix strands directly attacking DNA, so cisplatin can arrest the base pairing process causing cell death and apoptosis ${ }^{(2)}$.

Its cytotoxic destructive effects extended to the normal cells also, that cause hepatotoxicity, nephrotoxicity, neurotoxicity, and ototoxicity. However, the mechanism of hepatotoxicity is not clear, it may be due to interfering with the antioxidant defense process that causing oxidative stress $(3,4)$. Oxidative stress caused by cisplatin is due to exhaustion of the antioxidant systems either enzymatic or non-enzymatic like superoxide dismutase and glutathione peroxidase. This leads to accumulation of free radical, which is the main cause of biological molecules destruction (as lipid and protein), DNA destruction and overproduction of inflammatory cytokines ${ }^{(5)}$. Moreover, reactive oxygen species (ROS) are the main cause of lipid peroxidation ${ }^{(6)}$. Resveratrol (trans-3, 5, 40-trihydroxystilbene) is one of the polyphenols extract which has antioxidant and anti-inflammatory properties that could ameliorate the toxic adverse effects of cisplatin drug on liver ${ }^{(7)}$.

\section{MATERIALS AND METHODS}

Animals: Forty male albino rats at the same age, weighing 150-250 gm/each were kept in groups inside animal cages at room temperature; they were fed standard laboratory food and water.

\section{Ethical approval:}

All animals received appropriate care in compliance with the Public Health Service Policy on use of Laboratory Animals published by the National Institutes of Health and was approved by the Ethical Committee of the College of Medicine, Menoufia University, Egypt.

\section{Chemicals:}

Cisplatin and Resveratrol were brought from (Sigma-Aldrich) company, while Phosphate buffer was from (Biodiagnostic CO.).

\section{Induction of cisplatin toxicity:}

Animals were weighed and divided into four groups ( $\mathrm{n}=10$ for each). The treatment procedure was planned as:

- Group I (control group): was maintained throughout the experiment without any treatment.

- Group II (resveratrol group) that received resveratrol daily in a dose of $25 \mathrm{mg} / \mathrm{kg}$ intraperitoneally for 21 days.

- Group III (cisplatin group) that received single intraperitoneal injection of cisplatin in a dose of $7.5 \mathrm{mg} / \mathrm{kg}$ at the $16^{\text {th }}$ day of the experiment ${ }^{(8)}$.

- Group IV (protected group) that received resveratrol in a dose of $25 \mathrm{mg} / \mathrm{kg}$ intraperitoneally for 21 days and cisplatin at $16^{\text {th }}$ day of the experiment (on that day resveratrol dose was injected 30 minutes before cisplatin injection). 
Resveratrol was freshly prepared in $0.9 \%$ normal saline at a concentration of $20 \mathrm{mg}$ resveratrol $/ \mathrm{ml}$, $(0.2 \mathrm{ml} / \mathrm{rat})^{(9)}$.

At the end of the experiment, body weight for each rat was recorded before they were sacrificed. Venous blood samples were collected in heparinized capillary tubes from the retro-orbital plexus.

\section{Biochemical study}

The blood samples were centrifuged for $20 \mathrm{~min}$. Obtained serum was kept at $-80^{\circ} \mathrm{C}$ till biochemical analysis for liver function biomarkers comprising aspartate aminotransferase (AST), alanine aminotransferase (ALT), total bilirubin and direct bilirubin that were measured using spectrophotometric kits from (Biodiagnostic, Egypt).

Liver of each rat was dissected out, washed with saline, and weighed immediately. Half of liver sample was stored at $-80^{\circ} \mathrm{C}$ for biochemical analysis and the other half was put in formalin for histopathological study. The hepatosomatic index was estimated according to this formula:

\section{The hepatosomatic index $=$ rat liver weight $/$ rat body weight $x 100 \%{ }^{(10)}$}

Liver tissues (100 mg) were homogenized using a glass homogenizer in $(0.1 \mathrm{~mol} / \mathrm{l}, \mathrm{pH}$ 7.4) phosphate buffers then centrifuged at $1500 \times \mathrm{g}$ for $10 \mathrm{~min}$ and then at $10,000 \times \mathrm{g}$ for $15 \mathrm{~min}$ where the supernatant was used to measure the following parameters: superoxide dismutase (SOD) level and lipid peroxidation assay (MDA) using spectrophotometric kits from (Biodiagnostic, Egypt), the results were expressed in units/mg protein. Tumor necrosis factor alpha (TNF- $\alpha$ ) was measured using rat ELISA kits from (Chongqing Biospes Co., Ltd, China), the results were expressed in $\mathrm{pg} / \mathrm{ml}$.

\section{RT-PCR OF IL-10 (Interlukin-10):}

Total RNA was extracted from specimens using (QIAamp RNA Blood MiniKit, Qiagen, USA) according to manufacturer's instructions.

Two-step RT-PCR was done as follows:

For reverse transcription step, samples were prepared in a final volume of $20 \mathrm{ul}$ containing RT buffer, $5.5 \mathrm{mM} \mathrm{MgCl}_{2}, 500 \mathrm{mM}$ each dNTP, $2.5 \mathrm{mM}$ random hexamers, $0.4 \mathrm{U} / \mathrm{mL}$ RNase inhibitor, 1.25 $\mathrm{U} / \mathrm{mL}$ MultiScribe reverse transcriptase (PE Applied Biosystems), and $20 \mathrm{ng}$ total RNA. Then the samples were incubated at $25^{\circ} \mathrm{C}$ for 10 minutes and at $48^{\circ} \mathrm{C}$ for 30 minutes. Heating to $95^{\circ} \mathrm{C}$ for 5 minutes inactivated the reverse transcriptase on 2720 thermal cycler Singapore. For cDNA amplification the sequence of primers of interleukin 10, forward
CCAGGGCACCCAGTCTGACAA and TCGGAGATCTCGAAGCAT GT as reverse primer according to Genbank NC_000003 were used with SensiFASTTM SYBR ${ }^{\circledR}$ Lo-ROX Kit (Applied Biosystems, California, USA), nuclease free water, c DNA in a total reaction volume $25 \mathrm{ul}$ and using GAPDH as endogenous control.

Thermal cycling conditions comprised an initial incubation at $50^{\circ} \mathrm{C}$ for 2 minutes, AmpliTaq Gold activation at $95^{\circ} \mathrm{C}$ for 10 minutes, 40 cycles of denaturation at $95^{\circ} \mathrm{C}$ for 15 seconds, annealing and extension at $60^{\circ} \mathrm{C}$ for 1 minute. For relative quantification of the results obtained by RT-PCR, comparative cycle threshold $(\mathrm{Ct})$ method was used. Analysis was performed using Applied Biosystems 7500, software version 2.0.1. The point at which the PCR product is first detected above a fixed threshold, termed $\mathrm{Ct}$, was determined for each sample. Each run was completed using melting curve analysis to confirm specificity of the amplification and absence of primer dimmers.

\section{Histopathological study}

The other part of the liver was processed to prepare $5 \mu \mathrm{m}$ thick paraffin sections for (hematoxylin and eosin, H\&E), Masson's trichrome (MT) and Periodic acid Schiff (PAS) stains. Other sections were prepared for immunehistochemical staining with rabbit polyclonal anti-caspase $-3(\mathrm{ab} 13847)$ and mouse monoclonal anti - YAP (ab56701). Using the image J analyzer, five sections from each group were assessed for the morphometric study of area percentage for the positive reaction of (Masson's trichrome and PAS) stains, YAP immunehistochemical stain and for the number of caspase 3 immunopostive cells.

\section{Statistical analysis}

The collected data of all measured parameters were statistically analyzed using the SPSS program (version 20.0. Chicago, IL), results were expressed as mean \pm SD. Statistical evaluation for the difference between the two independent groups was carried out using Mann Whitney U test and the significance was considered when $\mathrm{P}$ value was lower than 0.05 .

\section{RESULTS}

Our results showed that there was no significant difference in all measured parameters between control group (GI) and resveratrol group (GII). Resveratrol treated cisplatin group (GIV) showed significant effect on the body weight, liver weight and the liver weight to body weight ratio compared with the cisplatin treated group (GIII) (Table: 1). 
Table (1): Resveratrol effect on the body weight, liver weight and liver weight to body weight ratio (mean \pm SD)

\begin{tabular}{|l|c|c|c|c|}
\hline \multicolumn{1}{|c|}{ Groups } & $\begin{array}{c}\text { Control group } \\
\text { (Group I) } \\
\text { N=10 }\end{array}$ & $\begin{array}{c}\text { Resveratrol } \\
\text { group } \\
\text { Parameters }\end{array}$ & $\begin{array}{c}\text { Cisplatin group } \\
\text { (Group III) } \\
\text { N=10 } \\
\text { N=10 }\end{array}$ & $\begin{array}{c}\text { Protected group } \\
\text { (Group IV) } \\
\text { N=10 }\end{array}$ \\
\hline $\begin{array}{l}\text { Body weight at the } \\
\text { beginning of the } \\
\text { experiment (gm) } \\
\text { P- Value }\end{array}$ & $157.0 \pm 4.92$ & $154.87 \pm 3.56$ & $158.5 \pm 5.42$ & $160.37 \pm 6.07$ \\
\hline $\begin{array}{l}\text { Body weight at the } \\
\text { end of experiment } \\
\text { (gm) } \\
\text { P- Value }\end{array}$ & $207.87 \pm 11.02$ & $196.37 \pm 13.56$ & $126.75 \pm 8.53$ & $161.50 \pm 11.38$ \\
\hline $\begin{array}{l}\text { Liver weight (gm) } \\
\text { P- Value }\end{array}$ & $7.3 \pm 0.53$ & $7.2 \pm 0.34$ & $9.43 \pm 0.39$ & $8.22 \pm 0.49$ \\
\hline $\begin{array}{l}\text { Liver weight/ body } \\
\text { weight ratio }\end{array}$ & $3.2 \pm 0.41$ & $3.64 \pm 0.15$ & $7.40 \pm 0.54$ & $\mathrm{P} 3<0.05$ \\
\hline \begin{tabular}{l} 
P- Value \\
\hline
\end{tabular} & & $\mathrm{P} 1>0.05$ & $\mathrm{P} 2<0.05$ & $5.10 \pm 0.52$ \\
\hline
\end{tabular}

P1: difference between resveratrol group (GII) to control group (GI), P2: difference between cisplatin group (GIII) to control group (GI) and P3: difference between protected group (GIV) to cisplatin group (GIII).

\section{Biochemical results:}

Measurement of the serum AST, ALT, total bilirubin, and direct bilirubin showed significant increase in cisplatin group (GIII) compared with control group (GI). Also, there was significant decrease in these parameters in protected group (GIV) (Table: 2).

Table (2): Resveratrol effect on serum measurement of aspartate aminotransferase (AST), alanine aminotransferase (ALT), total bilirubin and direct bilirubin in serum (mean \pm SD)

\begin{tabular}{|l|c|c|c|c|}
\hline \multicolumn{1}{|c|}{ Groups } & $\begin{array}{c}\text { Control group } \\
\text { (Group I) } \\
\mathbf{N = 1 0}\end{array}$ & $\begin{array}{c}\text { Resveratrol group } \\
\text { (Group II) } \\
\mathbf{N = 1 0}\end{array}$ & $\begin{array}{c}\text { Cisplatin group } \\
\text { (Group III) } \\
\mathbf{N}=\mathbf{1 0}\end{array}$ & $\begin{array}{c}\text { Protected group } \\
\text { (Group IV) } \\
\text { N=10 }\end{array}$ \\
\hline AST (IU/L) & $82.28 \pm 1.71$ & $82.85 \pm 1.09$ & $168.43 \pm 3.77$ & $124.75 \pm 2.38$ \\
P- Value & & $\mathrm{P} 1>0.05$ & $\mathrm{P} 2<0.05$ & $\mathrm{P} 3<0.05$ \\
\hline ALT (IU/L) & $38.15 \pm 1.71$ & $37.40 \pm 0.88$ & $148.26 \pm 4.66$ & $92.02 \pm 4.73$ \\
P- Value & & $\mathrm{P} 1>0.05$ & $\mathrm{P} 2<0.05$ & $\mathrm{P} 3<0.05$ \\
\hline $\begin{array}{l}\text { Total bilirubin } \\
\text { (mg/dl) }\end{array}$ & $0.41 \pm 0.06$ & $0.36 \pm 0.03$ & $1.88 \pm 0.34$ & $1.04 \pm 0.19$ \\
P- Value & & $\mathrm{P} 1>0.05$ & $\mathrm{P} 2<0.05$ & $\mathrm{P} 3<0.05$ \\
\hline $\begin{array}{l}\text { Direct bilirubin } \\
\text { (mg/dl) }\end{array}$ & $0.27 \pm 0.03$ & $0.23 \pm 0.05$ & $0.68 \pm 0.03$ & $0.54 \pm 0.05$ \\
P- Value & & & & $\mathrm{P} 2<0.05$ \\
\hline
\end{tabular}

P1: difference between resveratrol group (GII) to control group (GI), P2: difference between cisplatin group (GIII) to control group (GI) and P3: difference between protected group (GIV) to cisplatin group (GIII).

Measurement of the malondialdehyde (MDA) in liver tissue homogenate showed significant increase in cisplatin group (GIII) compared with the control group (GI). Moreover, there was significant decrease of MDA level in protected group (GIV). There was significant decrease of superoxide dismutase (SOD) in the cisplatin group (GIII) compared with the control group (GI). Also, there was significant increase of SOD in protected group (GIV). 
Moreover, the level of the tumor necrosis factor alpha (TNF- $\alpha$ ) in the liver tissue homogenate significantly increased in the cisplatin group (GIII) compared to the control group (GI). And there was significant decrease of TNF- $\alpha$ in protected group (GIV) compared to the cisplatin treated group (GIII). The relative quantitative RT-PCR of interlukin-10 (IL-10) measurement showed significant decrease of the IL-10 gene expression in cisplatin group (GIII) compared with control group (GI). But protected group showed significant increase of relative quantitative IL-10 gene expression (Table: 3 ).

Table (3): Resveratrol effect on malondialdehyde (MDA), superoxide dismutase (SOD), tumor necrosis factor $-\alpha$ and quantitative RT-PCR of interlukin-10 (IL-10) in the liver tissue homogenate (mean \pm SD)

\begin{tabular}{|l|c|c|c|c|}
\hline \multicolumn{1}{|c|}{ Groups } & $\begin{array}{c}\text { Control group } \\
\text { (Group I) } \\
\text { N=10 }\end{array}$ & $\begin{array}{c}\text { Resveratrol group } \\
\text { (Group II) } \\
\text { N=10 }\end{array}$ & $\begin{array}{c}\text { Cisplatin group } \\
\text { (Group III) } \\
\text { N=10 }\end{array}$ & $\begin{array}{c}\text { Protected group } \\
\text { (Group IV) } \\
\text { N=10 }\end{array}$ \\
\hline $\begin{array}{l}\text { MDA (nM/mg } \\
\text { tissue protein) } \\
\text { P- Value }\end{array}$ & $4.25 \pm 0.26$ & $4.01 \pm 0.21$ & $9.45 \pm 0.51$ & $6.41 \pm 0.74$ \\
\hline $\begin{array}{l}\text { SOD (U/mg } \\
\text { protein) } \\
\text { P- Value }\end{array}$ & $25.47 \pm 2.19$ & $26.09 \pm 1.93$ & $14.74 \pm 1.40$ & $22.26 \pm 1.68$ \\
\hline TNF- $\alpha$ (Pg/ml) & $15.47 \pm 1.01$ & $15.14 \pm 0.85$ & $44.10 \pm 4.89$ & $31.80 \pm 3.55$ \\
P- Value & $1 \pm 0.08$ & $1 \pm 0.13$ & $\mathrm{P} 2<0.001$ & $\mathrm{P} 3<0.001$ \\
\hline QRT-PCR IL-10 & & $\mathrm{P} 1=1.0$ & $0.58 \pm 0.09$ & $1.31 \pm 0.22$ \\
P- Value & & $\mathrm{P} 2<0.001$ & $\mathrm{P} 3<0.001$ \\
\hline
\end{tabular}

P1: difference between resveratrol group (GII) to control group (GI), P2: difference between cisplatin group (GIII) to control group (GI) and P3: difference between protected group (GIV) to cisplatin group (GIII).

\section{Histopathological results:}

Hematoxylin and eosin stain (H\&E stain):

Light microscopic examination of H\&E-stained liver sections of control group showed polygonal hepatocytes with (vesicular nuclei and acidophilic cytoplasm) arranged in cords radiating from central vein and separated by blood sinusoids forming the classic hepatic lobule. The portal tract appeared at the periphery of the lobule containing portal vein tributary, hepatic artery, and bile duct branches (Fig. 1A-C).

While the liver sections of cisplatin group showed loss of normal architecture, vacuolations of hepatocytes, pyknosis and degeneration of their nuclei. The portal tract showed proliferation of its components (bile duct and hepatic artery branches) and infiltration with mononuclear inflammatory cells. Also, the portal vein tributary revealed dilatation and congestion (Fig. 2A-C). The protected group showed preservation of the normal architecture with vacuolations of some hepatocytes (Fig. 3A-C). 

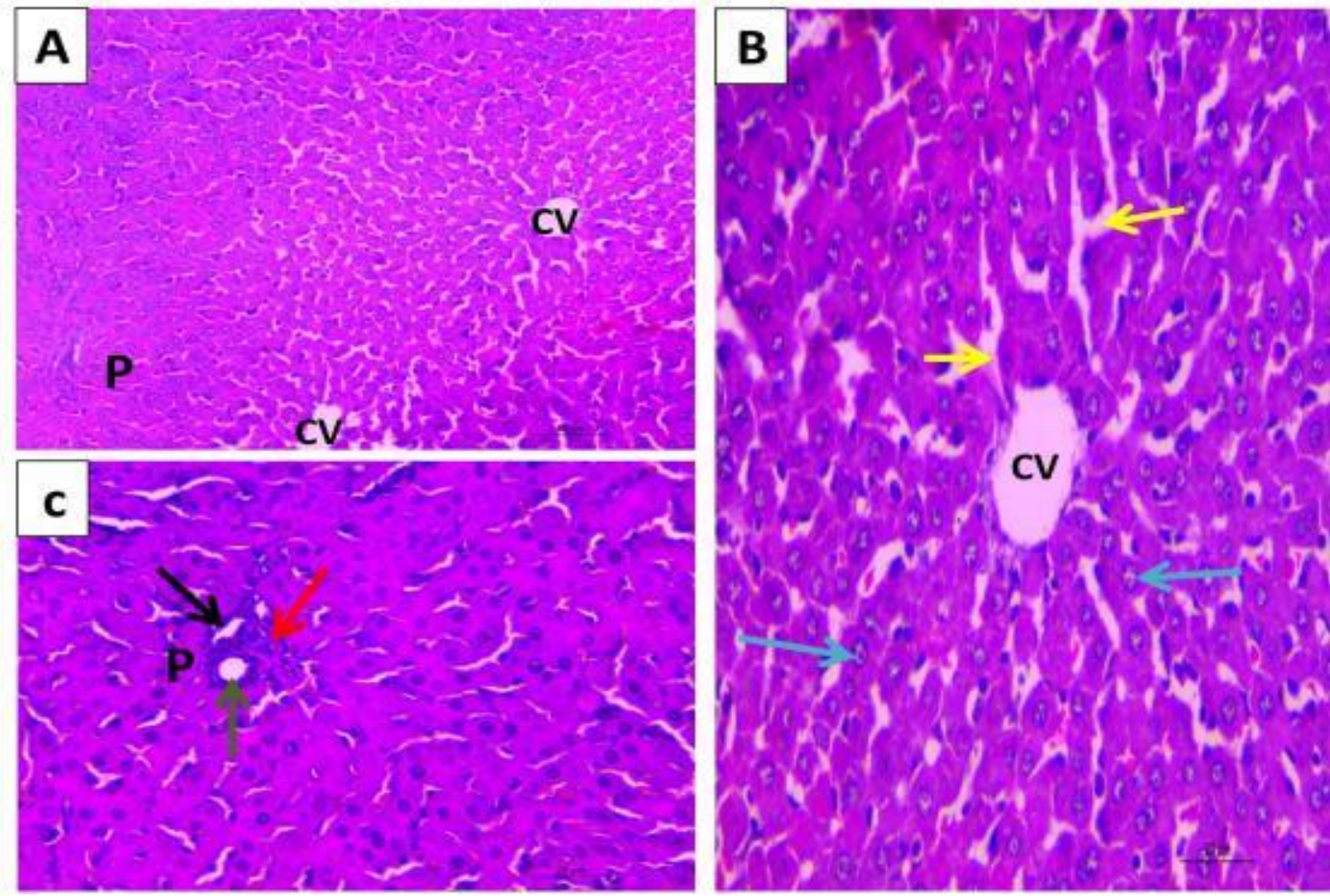

Fig. (1): H\&E-stained liver section of control group revealing the polygonal hepatocytes with vesicular nuclei (blue arrow), radiating from central vein $(\mathrm{CV})$ separated by blood sinusoids (yellow arrow) reaching the portal tract $(\mathrm{P})$ containing the portal vein tributary (black arrow), hepatic artery (red arrow) and bile duct (green arrow) branches. $(\mathrm{A} ; \mathrm{x} 200)$ and $(\mathrm{B}, \mathrm{C} ; \mathrm{x} 400)$
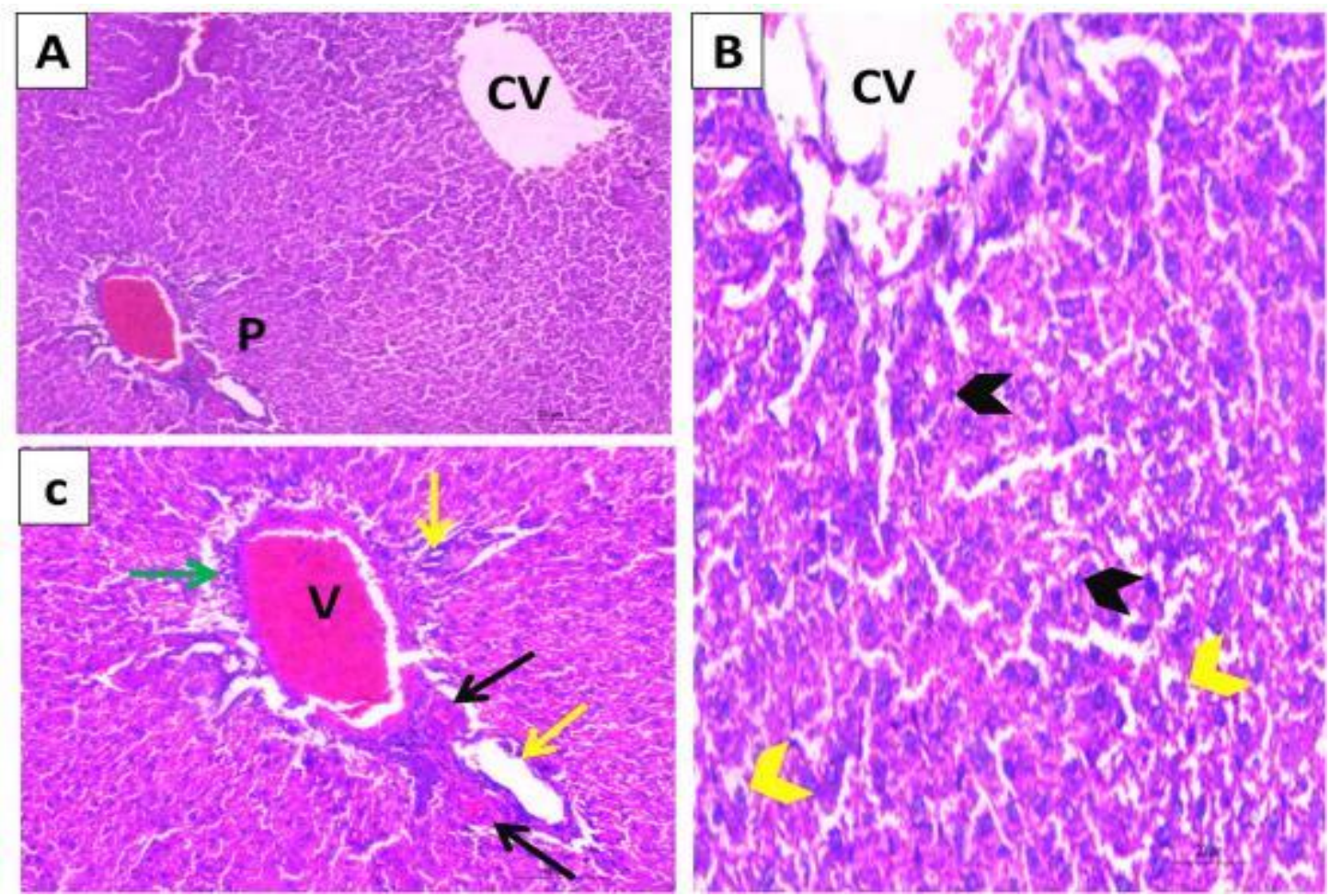

Fig. (2): H\&E-stained liver section of cisplatin group showing the loss of normal architecture, dilatation of central vein $(\mathrm{CV})$, some hepatocytes have vacuolated cytoplasm with degenerated (yellow arrowhead) and pyknotic (black arrowhead) nuclei. The portal tract $(\mathrm{P})$ is infiltrated with mononuclear inflammatory cells (green arrow) containing the dilated congested portal vein tributary $(\mathrm{V})$, proliferated hepatic artery (black arrow) and bile duct (yellow arrow) branches. (A; x100), (B; x200) and (C; x400) 

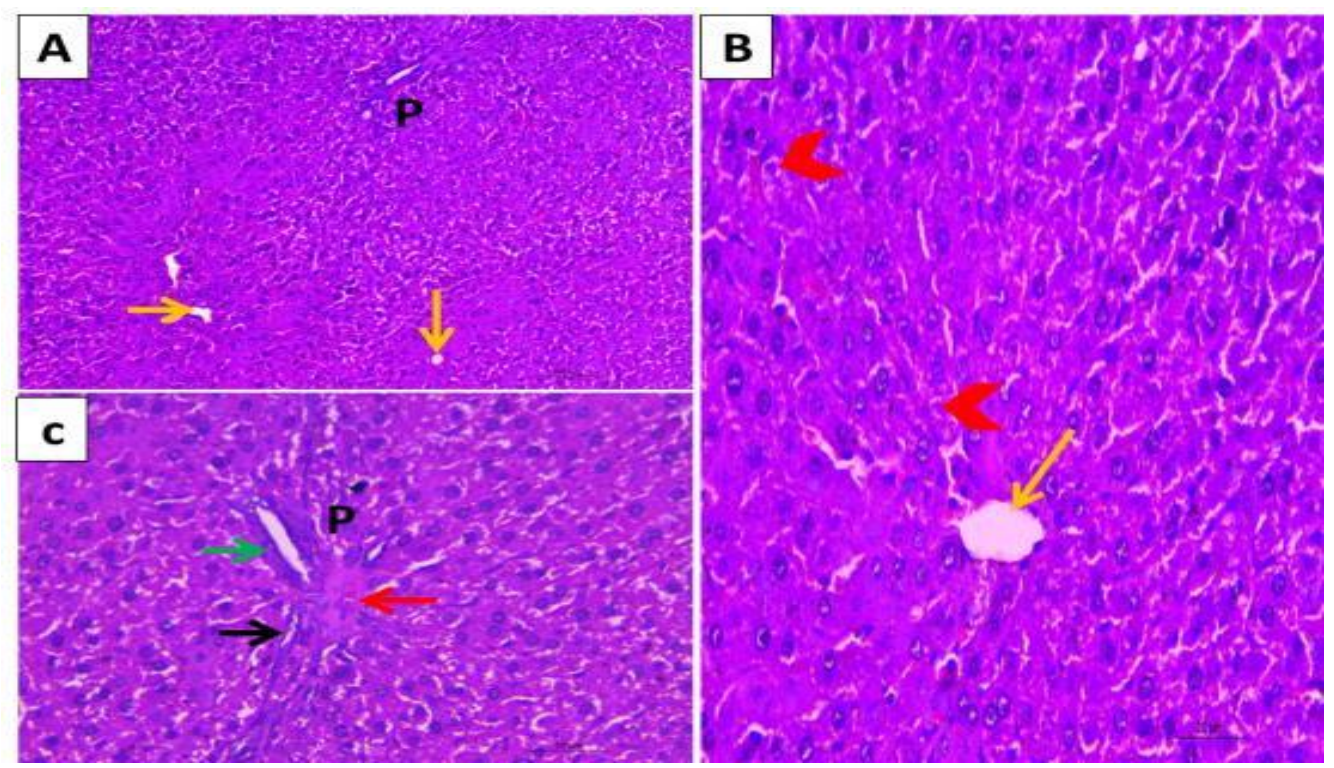

Fig. (3): H\&E-stained liver section of protected group showing preservation of normal central vein (yellow arrow), some hepatocytes have vacuolated cytoplasm and degenerated nuclei (red arrowhead). The normal elements of portal tract (P); hepatic artery (red arrow) and bile duct (green arrow) branches and portal vein tributary (black arrow) can be observed. (A; $\mathrm{x} 200)$ and $(\mathrm{B}, \mathrm{C} ; \mathrm{x} 400)$

\section{Masson's trichrome stain:}

The liver sections of cisplatin group revealed significant increase in the area percentage of Masson's trichrome stain in the portal tract and vessels wall as compared to control group. While the resveratrol treatment caused significant decrease in the area percentage of Masson's trichrome stain in the portal tract and vessels wall as compared to cisplatin group (Fig. 4A-D).
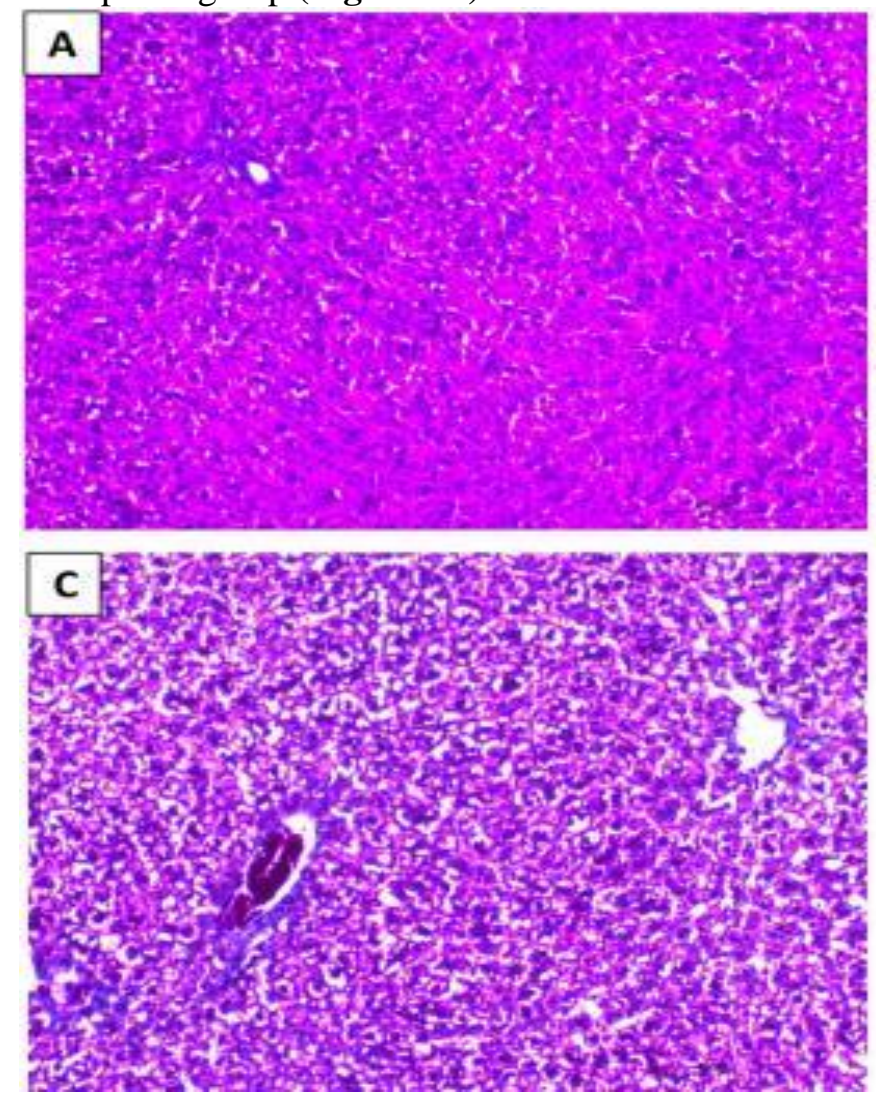
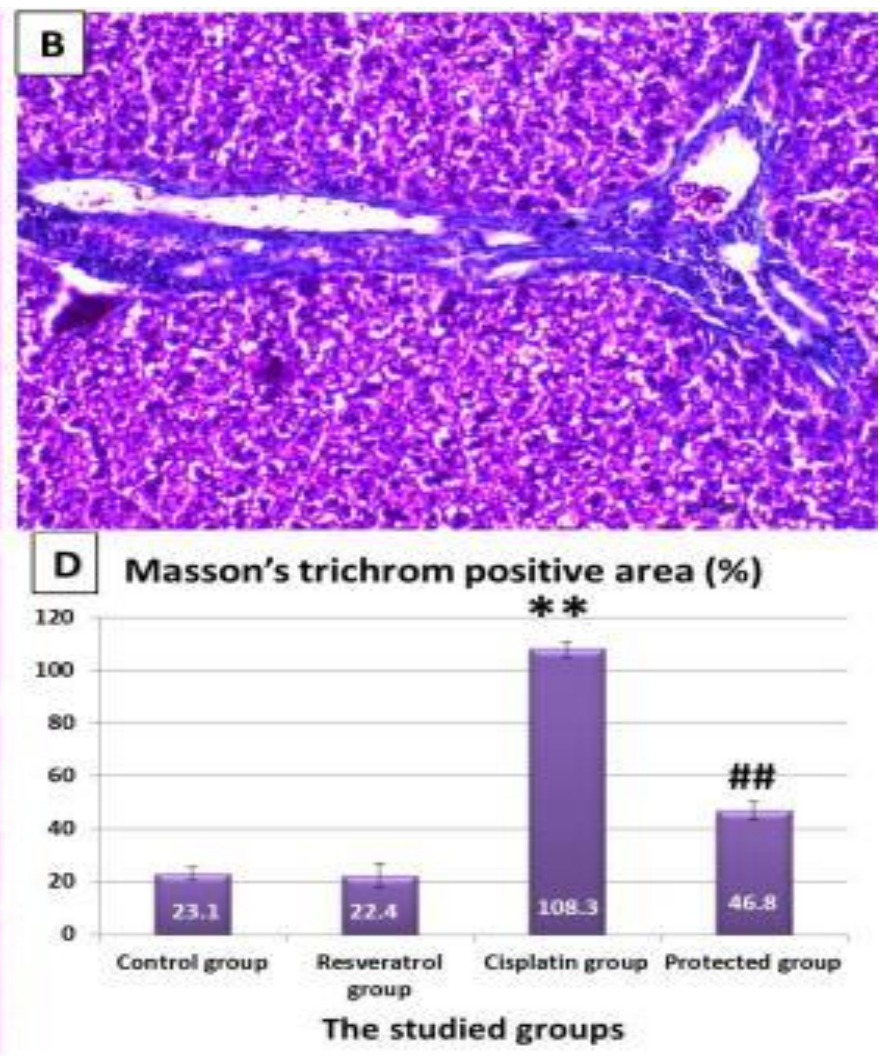

Fig. (4): Masson's trichrome stained liver sections of different groups:

The cisplatin group (GIII, B and D) showed significant increase $(* * p$ value $<0.001)$ in the Masson's trichrome positively stained area percentage as compared to control group (GI, A). While the protected group (GIV, C and D) showed significant decrease (\#\#p value $<0.001$ ) in the Masson's trichrome positively stained area percentage as compared to cisplatin group (GIII, B) (A, B, C; x 200). 


\section{Periodic acid Schiff stain (PAS):}

The cisplatin group showed significant decrease in the area percentage of PAS reaction in the hepatocytes as compared to control group. While the resveratrol treatment caused significant increase in the area percentage of PAS reaction in the hepatocytes as compared to cisplatin group (Fig. 5A-D).
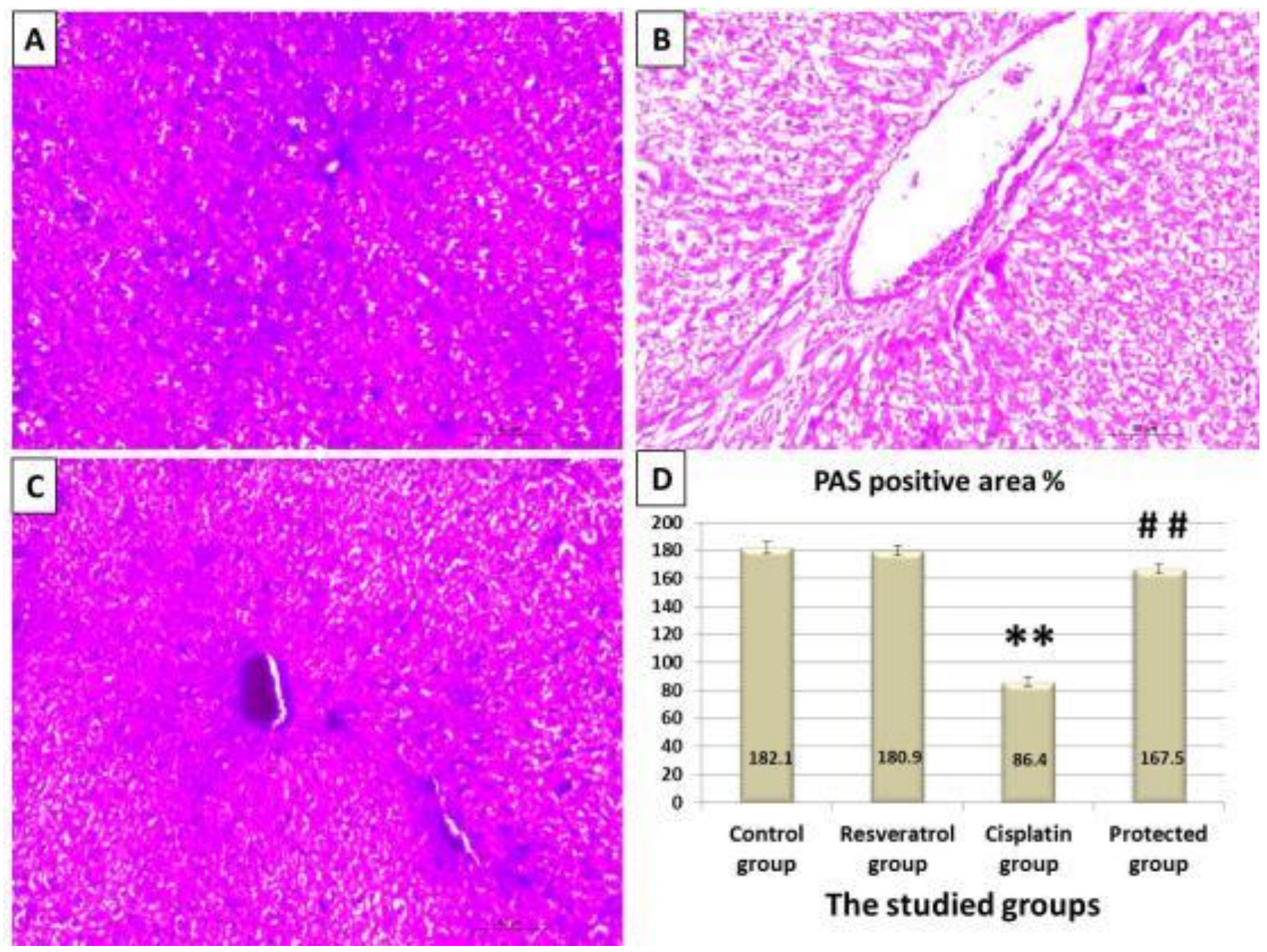

Fig. (5): Periodic acid Schiff-stained liver sections of different groups:

The cisplatin group (GIII, B and D) showed significant decrease (**p value $<0.001)$ in the periodic acid Schiff positively stained area percentage as compared to control group (GI, A). While the protected group (GIV, C and D) showed significant increase (\#\#p value $<0.001)$ in the periodic acid Schiff positively stained area percentage as compared to cisplatin group (GIII, B) (A, B, C; x 200).

\section{Immunohistochemical stains (caspase 3 and YAP):}

The cisplatin group showed significant increase in the number of caspase 3 immunopositive hepatocytes as compared to control group. While the resveratrol treatment caused significant decrease in the number of caspase 3 immunopositive hepatocytes as compared to cisplatin group (Fig. 6A1-A3) and (Fig. 7).

The cisplatin group showed significant increase in the number of YAP immunopositive hepatocytes and portal tract fibroblasts as compared to control group. While the resveratrol treatment caused significant decrease in the number of YAP immunopositive hepatocytes and portal tract fibroblasts as compared to cisplatin group (Fig. 6B1B3) and (Fig. 7). 


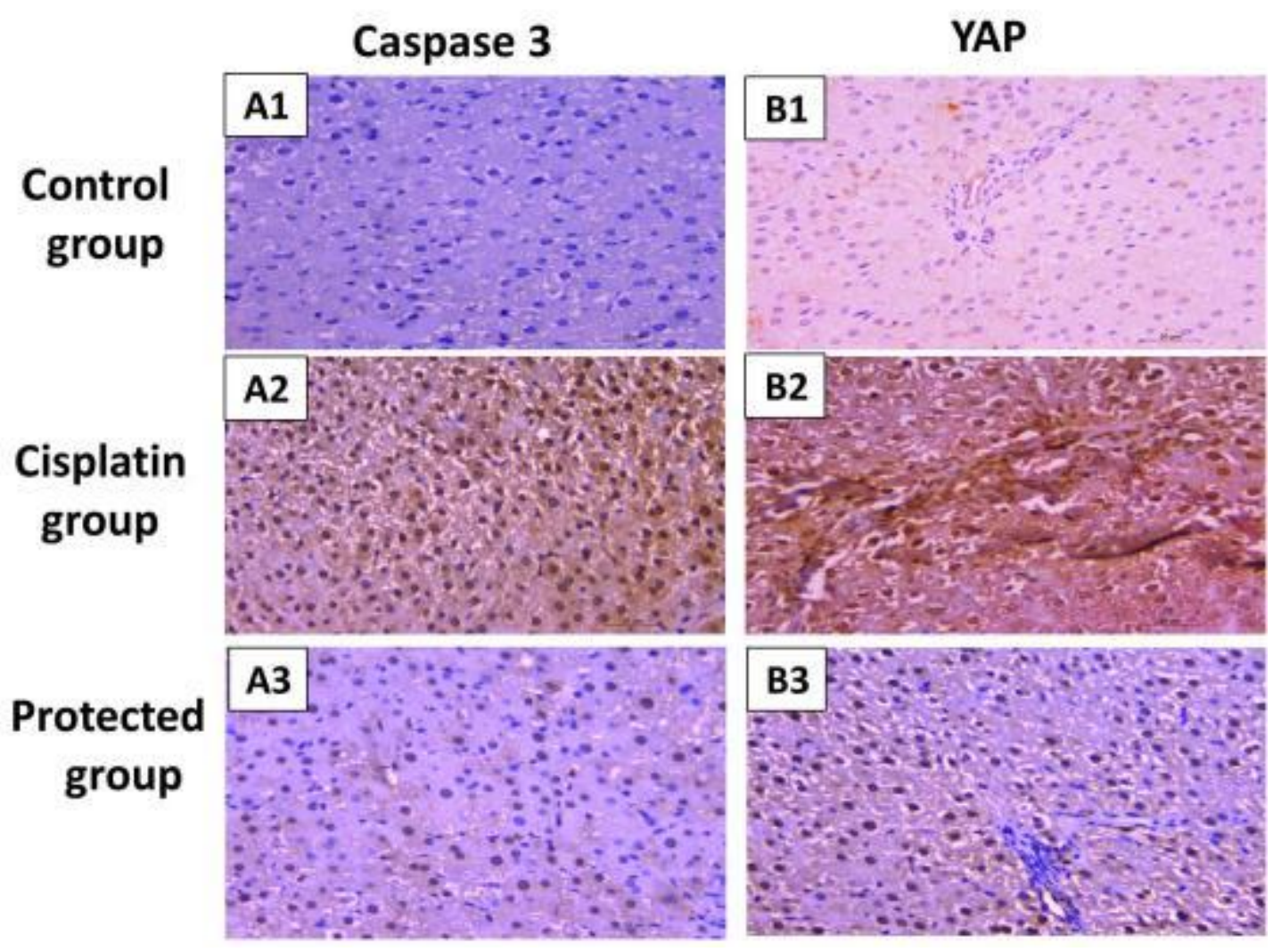

Fig. (6): Immunohistochemically stained liver sections of different groups: The cisplatin group [GIII, (A2, B2)] showed significant increase in caspase 3 and YAP positively stained cells as compared to control group [GI, (A1, B1)]. While the protected group [GIV, (A3, B3)] showed significant decrease in caspase 3 and YAP positively stained cells as compared to cisplatin group [GIII, (A2, B2)]. (Caspase 3 and YAP immunehistochemical stains; $x$ 400)

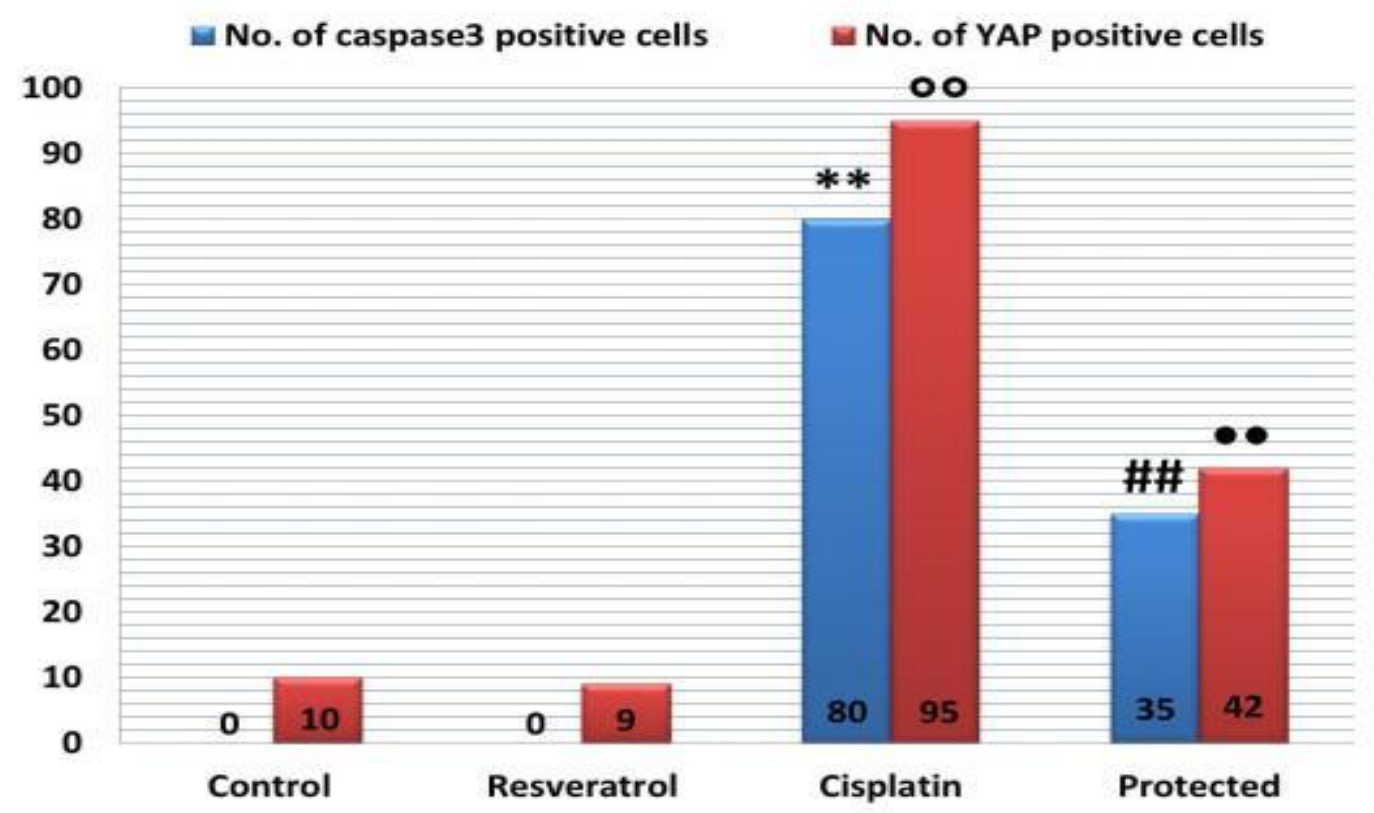

Fig. (7): Representative expression of caspase 3 and YAP in the liver sections of different groups:

**p and ${ }^{\circ 0} \mathrm{p}$ values $<0.001$ of significant increase in cisplatin group (GIII) as compared to control group (GI). \#\#p and $\bullet p$ values $<0.001$ of significant decrease in protected group (GIV) as compared to cisplatin group (GIII). 


\section{DISCUSSION}

Hepatocytes injury during cisplatin treatment is a great issue, this side effect should be investigated to prevent stoppage of the drug during the treatment protocol. In our study, the rats of cisplatin group showed physical weakness, loss of their body weight and moreover significant increase in the liver weight as compared with control group, all these findings might be owed to the toxic adverse effects of the cisplatin as reported by $\mathbf{L u}$ and Cederbaum ${ }^{(11)}$. Also, hematoxylin and eosin stained liver sections of cisplatin group showed vacuolations of the hepatocytes which might be explained by the phospholipidosis (intracellular deposition of lipid droplets), which is a trial to collect and combat the toxic compound $(\mathbf{1 2}, \mathbf{1 3})$. The lipid infiltration of hepatocytes might lead to cellular injury and release of liver enzymes into the blood ${ }^{(14)}$, this explained the significant increase of serum (ALT and AST) of cisplatin group as compared to control group. The hepatocyte injury might extend to (the cell membrane, mitochondria, and nuclear DNA) leading to release of reactive oxygen species (ROS), lipid phosphorylation causing oxidative stress, inflammation, and vascular endothelial dysfunction (15-17). This explained (the inflammatory infiltrate and vascular changes) of the H\&E-stained liver sections as well as the significant (increase of the pro-inflammatory cytokine TNF- $\alpha$ and decrease in the gene expression of the antiinflammatory cytokine IL-10) in the liver homogenate of cisplatin group as compared to control group. The oxidative stress and the apoptosis were confirmed in our study biochemically by the significant increase of MDA and decrease of SOD in the liver of cisplatin group as compared to that of control group and histologically by the pyknosis of hepatocytes nuclei in H\&E-stained liver sections of cisplatin group. Also, immunohistochemically an apoptotic marker (caspase 3) was used in our study and revealed significant increase in the number of caspase 3 positively stained hepatocytes in cisplatin group as compared to the control group. The liver dysfunction was clarified by the morphometric analysis of PAS-stained liver sections to detect the significant decrease of PAS reaction in the liver of cisplatin group denoting minimal amount of stored glycogen as the synthesis and storage of glycogen granules are the functions of normal hepatocytes (18) as compared to the control group. The inflammatory cytokines (as TNF $\alpha$, released by the inflammatory cells) led to deposition of connective tissue (mainly collagen I) causing fibrosis in the inflamed area ${ }^{\left({ }^{(9)}\right.}$, this explained the significant increase of percentage of Masson's trichrome positively stained area especially in the portal tract together with the number of YAP positively immunestained hepatocytes and fibroblast. YAP is a profibrotic immunohistochemical marker, it is minimally expressed in the normal liver indicating the continuous process of regeneration ${ }^{(20)}$. YAP enhances the conversion of hepatocytes into hepatic progenitor stem cell (HPC) to induce the healing after the injury, HPC produces more extracellular matrix causing the fibrosis (21). Our study also revealed significant increase in the serum bilirubin which was supported by proliferation of bile duct branches in H\&E-stained liver sections of cisplatin group. This was explained by the fibrogenic and mitogenic effects of bile acids, which were liberated through the extension of liver damage to the intrahepatic bile ducts ${ }^{(22)}$. The bile acids stimulate the hyperplasia of the myofibroblast cells (hepatic stellate cells; HSC) causing the fibrosis leading to cholestasis and compensatory bile duct proliferation) ${ }^{(23,24)}$. These observed results were not found in the protected group, this suggested that resveratrol has a protective effect during cisplatin adverse effects. The present study recorded that pretreatment and post treatment the cisplatin group with resveratrol significantly increase the level of superoxide dismutase, which is a key antioxidant enzyme. Leonard et al. ${ }^{(25)}$ suggested that resveratrol protect against free radicals by enhancement the production of antioxidant enzymes like SOD, CAT and glutathione peroxidase. Moreover, resveratrol treated cisplatin group showed significantly decreased the MDA level which is considered as index of lipid peroxidation due to over production of ROS and free radicals. ROS is considered as the main cause of liver damage during cisplatin treatment schedule. These results run parallel to Seif El-Din et al. (26) who suggested that resveratrol as antioxidant natural product could normalize the levels of SOD and MDA.

Resveratrol possess anti-inflammatory activity through inhibition of the production of the pro inflammatory cytokines and also resveratrol suppresses the expression of NF- $\mathrm{kB}, \mathrm{AP}-1$ and apoptosis ${ }^{(27)}$. The results of this study showed that the treatment of the cisplatin group with resveratrol significantly decreased TNF- $\alpha$ compared with cisplatin treated group, these results run parallel to Palacz-Wrobel et al. (28) who suggested that resveratrol could suppress expression and the production of TNF- $\alpha$ from macrophages by blocking gene expression of that cytokine.

Moreover, the current study showed that the cisplatin treated group with resveratrol showed significantly increase in the IL-10 gene expression in the liver tissue homogenate compared with cisplatin group, previous study suggested that resveratrol in small doses had the ability to elevate IL-10 secretion through enhancement of gene expression and increase the mRNA copies of IL-10 ${ }^{(29)}$.

\section{CONCLUSION}

Therefore, it might be concluded that resveratrol could protect the liver during cisplatin 
treatment from injurious inflammatory cytokines through the enhancement of the antioxidant enzyme activity.

\section{REFERENCES}

1. Siddik Z (2003): Cisplatin: mode of cytotoxic action and molecular basis of resistance. Oncogene, 22(47):7265-79.

2. Melnikov S, Steitz T, Polikanov Y (2016): Insights into RNA binding by the anticancer drug cisplatin from the crystal structure of cisplatin-modified ribosome. Nucleic Acids Res., 44(10):4978-87.

3. Kintzel P(2001): Anticancer drug induced kidney disorders. Drug Saf., 24(1):19-38.

4. Rabik C, Dolan M. (2007): Molecular mechanisms of resistance and toxicity associated with platinating agents. Cancer Treat Rev., 33(1):9-23.

5. El-Beshbishy H, Aly H, Fakher H (2011): Abrogation of cisplatin-induced nephrotoxicity in mice by alpha lipoic acid through ameliorating oxidative stress and enhancing gene expression of antioxidant enzymes. Eur J Pharmacol., 668(1-2):278-84.

6. Marnett L (2000): Oxyradicals and DNA damage. Carcinogenesis, 21(3):361-70.

7. Sener G, Toklu H, Sehirli A et al. (2006): Protective effects of resveratrol against acetaminophen-induced toxicity in mice. Hepatol Res., 35: 62-68.

8. Afsar T, Razak S, Almajwal A et al. (2017): Modulatory influence of Acacia hydaspica R. Parker ethyl acetate extract against cisplatin inveigled hepatic injury and dyslipidemia in rats. BMC Complement Altern Med., 17(1):307.

9. Do Amaral C, Francescato H, Coimbra T et al. (2008): Resveratrol attenuates cisplatin-induced nephrotoxicity in rats. Arch Toxicol., 82(6):363-70.

10. Kannan N, Sakthivel K, Guruvayoorappan C (2013): Protective effect of Acacia nilotica (L.) against acetaminophen-induced hepatocellular damage in wistar rats. Adv Pharmacol Sci., 13:1-9.

11. Lu Y, Cederbaum A (2006): Cisplatin-Induced hepatotoxicity is enhanced by elevated expression of cytochrome P450 2E1.Toxicol Sci., 89(2):515-523.

12. Mahmoud B, Kefafy M, Yassien R et al. (2016): Light and electron microscopic study on the effect of ketoconazole on the liver of adult male albino rats. Menoufia Medical Journal, 29 (4): 929-935.

13. Togashi Y, Imura N, Sai $\mathrm{T}$ et al. (2013): Immunohistochemistry of LAMP-2 and adipophilin for phospholipidosis in liver and kidney in ketoconazoletreated mice. Exp Toxicol Pathol., 65:817-823.

14. Zubairi M, Ahmed J, Al-Haroon S (2014): Effect of adrenergic blockers, carvedilol, prazosin, metoprolol and combination of prazosin and metoprolol on paracetamolinduced hepatotoxicity in rabbits. Indian J Pharmacol., 46:644-8.

15. Al-Griw M, Alghazeer R, Al-Azreg S et al. (2016): Cellular and molecular etiology of hepatocyte injury in a murine model of environmentally induced liver abnormality. Open Vet J., 6(3): 150-157.
16. Mittal M, Tran M, Reddy S et al. (2014): Reactive Oxygen Species in Inflammation and Tissue Injury. Antioxid Redox Signal., 20(7): 1126-1167.

17. Shmarina G, Pukhalsky A, Kokarovtseva $S$ et al. (2001): Tumor necrosis factor-alpha/interleukin-10 balance in normal and cystic fibrosis children. Mediators Inflamm., 10(4): 191-197.

18. El Morsey D, Abou-Rabia N, Khalaf G et al. (2019): Histological study on the possible protective role of Moringa Oleifera leaves extract on paracetamol induced liver damage in adult male albino rats. EJHM., 42 (3):712729.

19. Komolkriengkrai M, Nopparat J, Vongvatcharanon $U$ et al. (2019): Effect of glabridin on collagen deposition in liver and amelioration of hepatocyte destruction in diabetes rats. Experimental and Therapeutic Medicine, 18(2): 1164-1174.

20. Machado M, Michelotti G, Pereira T et al. (2015): Accumulation of duct cells with activated YAP parallels fibrosis progression in non-alcoholic fatty liver disease. $\mathrm{J}$ Hepatol., 63(4):962-70.

21. Williams M, Clouston A, Forbes S (2014): Links between hepatic fibrosis, ductular reaction, and progenitor cell expansion. Gastroenterology, 146:349-56.

22. Massimo P, Tu P, Luongb V (2018): Pathogenesis of biliary fibrosis. Biochimica et Biophysica Acta (BBA) Molecular Basis of Disease, 1864 (4): 1279-1283.

23. Svegliati-Baroni G, Ridolfi F, Hannivoort $\mathrm{R}$ et al. (2005): Bile acids induce hepatic stellate cell proliferation via activation of the epidermal growth factor receptor. Gastroenterology, 128:1042-1055.

24. Roskams T, Theise N, Balabaud C (2004): Nomenclature of the finer branches of the biliary tree: canals, ductules, and ductular reactions in human livers. Hepatology, 39: 1739-1745.

25. Leonard S, Xia C, Jiang B et al. (2003): Resveratrol scavenges reactive oxygen species and effects radicalinduced cellular responses. Biochem Biophys Res Commun., 309:1017-1026.

26. Seif El-Din S, El-Lakkany N, Salem M et al. (2016): Resveratrol mitigates hepatic injury in rats by regulating oxidative stress, nuclear factor-kappa B, and apoptosis. J. Adv. Pharm. Technol. Res., 7(3):99-104.

27. Manna S, Mukhopadhyay A, Aggarwal B (2000): Resveratrol suppresses TNF- $\alpha$ induced activation of nuclear transcription factors NF-kappa B, activator protein-1, and apoptosis: potential role of reactive oxygen intermediates and lipid peroxidation, J. Immunol., 164: 6509-6519.

28. Palacz-Wrobel M, Borkowska P, Paul-Samojedny M et al. (2017): Effect of apigenin, kaempferol and resveratrol on the gene expression and protein secretion of tumor necrosis factor alpha (TNF- $\alpha$ ) and interleukin-10 (IL-10) in RAW-264.7 macrophages. Biomed Pharmacother., 93:1205-1212.

29. Bolger A, Sharma R, Von Haehling S et al. (2002): Effect of interleukin-10 on the production of tumor necrosis factor-alpha by peripheral blood mononuclear cells from patients with chronic heart failure. Am J Cardiol., 90(4):384-389. 